\title{
Characteristics of External Loop Sensor Located Near Bushing on Partial Discharge Induced Electromagnetic Wave Measurement
}

\author{
Sriyono $^{1,2,3}$, Yong-Joo Kim ${ }^{2,4}$, Umar Khayam ${ }^{1}$, Suwarno ${ }^{1}$, Masayuki Hikita ${ }^{2}$ \\ ${ }^{1}$ School of Electrical Engineering and Informatics, Institut Teknologi Bandung, Indonesia \\ ${ }^{2}$ Department of Electrical Engineering, Kyushu Institute of Technology, Japan \\ ${ }^{3}$ PT PLN (Persero), Indonesia \\ ${ }^{4}$ Korea Electrotechnology Research Institute, Korea \\ umar@hv.ee.itb.ac.id
}

\begin{abstract}
For transmitting a huge electrical energy, high voltage transmission systems are commonly operated. Due to high reliability and less space required, gas insulated substation (GIS) are widely used. In a defect experienced GIS, partial discharge (PD) usually takes place. Partial discharge (PD) monitoring technique using UHF method becomes more popular because of its higher signal to noise $(\mathrm{S} / \mathrm{N})$ ratio. Amongst novel sensors, loop sensor could be a candidate for PD detector to measure UHF signal emitted from PD source. This paper presents the experiment results on characteristics of loop sensors. The characteristics of three loop sensors with varying diameter were examined using a spectrum analyzer and a network analyzer to obtain frequency characteristic and optimum operating frequency (S11) parameter, respectively. Then, PD experiment was conducted on $66 \mathrm{kV}$ GIS model having floating electrode and free metallic particles as its PD source. The loop sensors were placed far external to GIS bushing to measure leaked PD signal from it. The influences of the sensor diameter and the sensor distance from GIS bushing on PD detection sensitivity were also examined. Based on IEC-60270 standard measurement, the highest sensitivity of $30 \mathrm{pC}$ was obtained from this investigation. The result suggests that higher sensitivity could be achieved with proper shielding and suitable filter design against external noise.
\end{abstract}

Keywords: Partial discharge; loop sensor; frequency characteristic, gas-insulated substation; sensitivity; zero span modes.

\section{Introduction}

For transmitting a huge electrical energy, high voltage transmission systems are commonly operated. Due to high reliability and less space required, gas insulated substation (GIS) are widely used. During operation partial discharge (PD) may take place in GIS. The PD occurrence is an indication of GIS abnormality. Partial discharge (PD) detection is the most effective method to monitor and diagnose the insulation condition of high voltage apparatus[18]. PD detection method is of importance among the various diagnostic techniques, since it is non-destructive, non-intrusive and can qualitatively describe the integrity of insulation system.One of the promising PD diagnostic techniques is the ultrahigh frequency (UHF) electromagnetic wave detection method that has been widely used for measuring insulation performance in gas-insulated switchgear (GIS) due to its advantageous characteristics, such as high sensitivity, wide detection range and less external disturbances [9-19].

One of the most important part of PD measurement system is sensors. Sensors strongly influence the sensitivity of PD measurement system. Some experiments on detecting characteristics of various types antenna have already been conducted [10]. Loop sensor is one of PD detectors to measure UHF signal emitted from partial discharge source.

This paper presents the frequency characteristics and S11 parameter of loop sensor with varying the diameter. Then, the laboratory results on $66 \mathrm{kV}$ GIS model having floating electrode and free metallic particles as PD source will be shown afterwards. The loop sensors

Received: August $10^{\text {th }}, 2012$. Accepted: March $24^{\text {th }}, 2013$ 
Sriyono, et al.

were placed far external to GIS busing to measure leaked PD signal from it. Based on IEC60270 standard measurement, we verify the sensitivity of the sensors corresponding to apparent charge.

\section{Loop Sensor and its Characteristics}

An antenna in a radio application is needed for two main reasons: to transmit and to receive signal. A small loop coil could be functioned as both transmitting and receiving antenna utilizing near field magnetic induction coupling. However, in PD application, small loop sensor is needed only for receiving UHF signal. When time-varying magnetic field is passing through a coil, it induces voltage across a coil terminal. A loop sensor must be designed to maximize this induced voltage for the case of frequency resonance type. However, for PD sensor requiring flat frequency reponse, resonance frequency band should be avoided by adequate design process.

Based on Faraday's law, a time-varying magnetic field through a surface bounded by a closed path induces a voltage around the loop as expressed by equations (1) and (2).

$$
\begin{aligned}
& V_{\text {ind }}=-N \frac{d \Psi}{d t} \\
& \Psi=\int B \cdot d S
\end{aligned}
$$

where : $\mathrm{N}=$ number of turns, $\Psi=$ magnetic flux, $\mathrm{B}=$ magnetic field, and $\mathrm{S}=$ surface area.

In this experiment, three loop sensors having diameter of $5 \mathrm{~cm}, 8 \mathrm{~cm}$ and $13 \mathrm{~cm}$ were examined using a spectrum analyzer and a network analyzer to obtain the distance and size effects of the sensors on sensitivity and S11 parameter, as shown in Figure 1.Using a network analyzer (Advantest R3765CG up to $3.8 \mathrm{GHz}$ ), S11 of three loop sensors were measured . The results are shown in Figure2. (a), (b), and (c).The result surely explains that the three loop sensors have their own resonance frequencies.

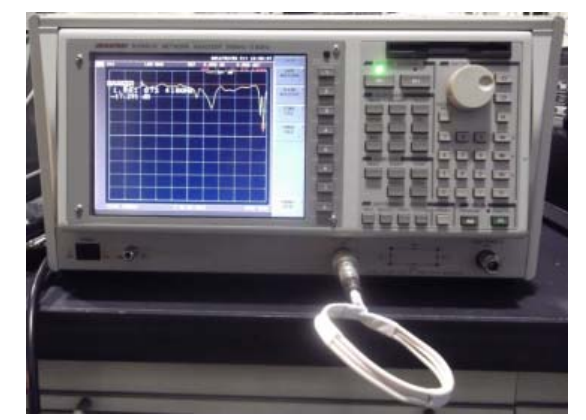

(a). S11 parameter measurement

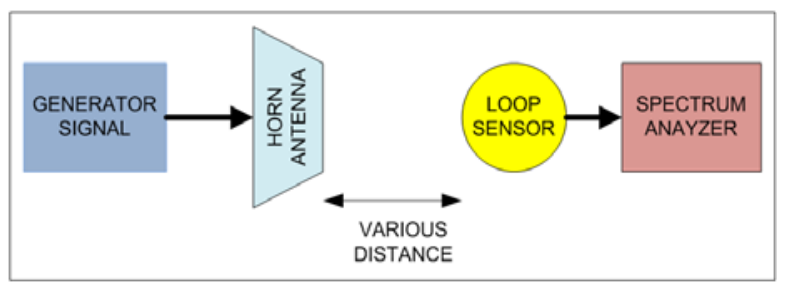

(b). Setup for distance and size effects measurement $(500 \mathrm{MHz} 3 \mathrm{GHz}$ )

Figure 1. Setup for (a) S11 (b) distance and size effect measurement 


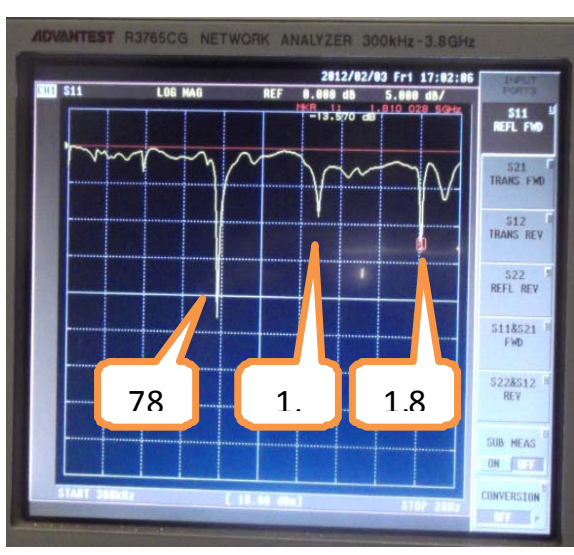

(a)

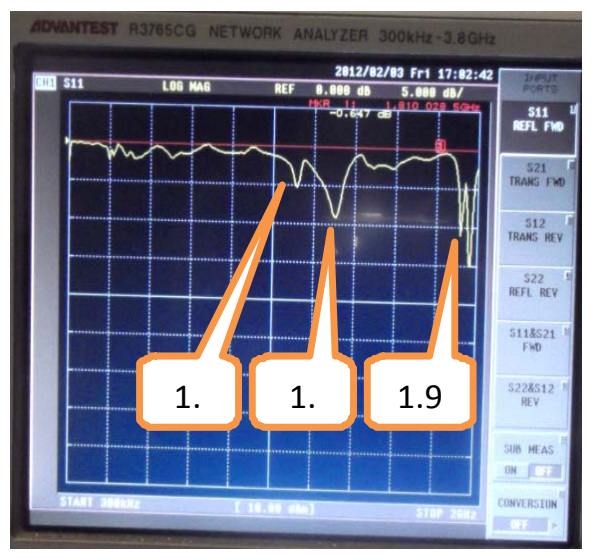

(b)

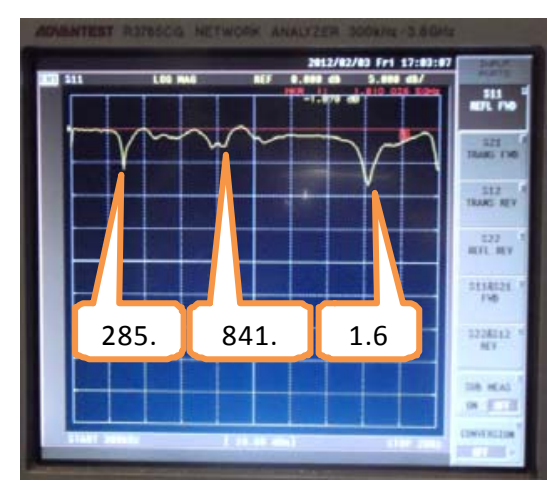

(c)

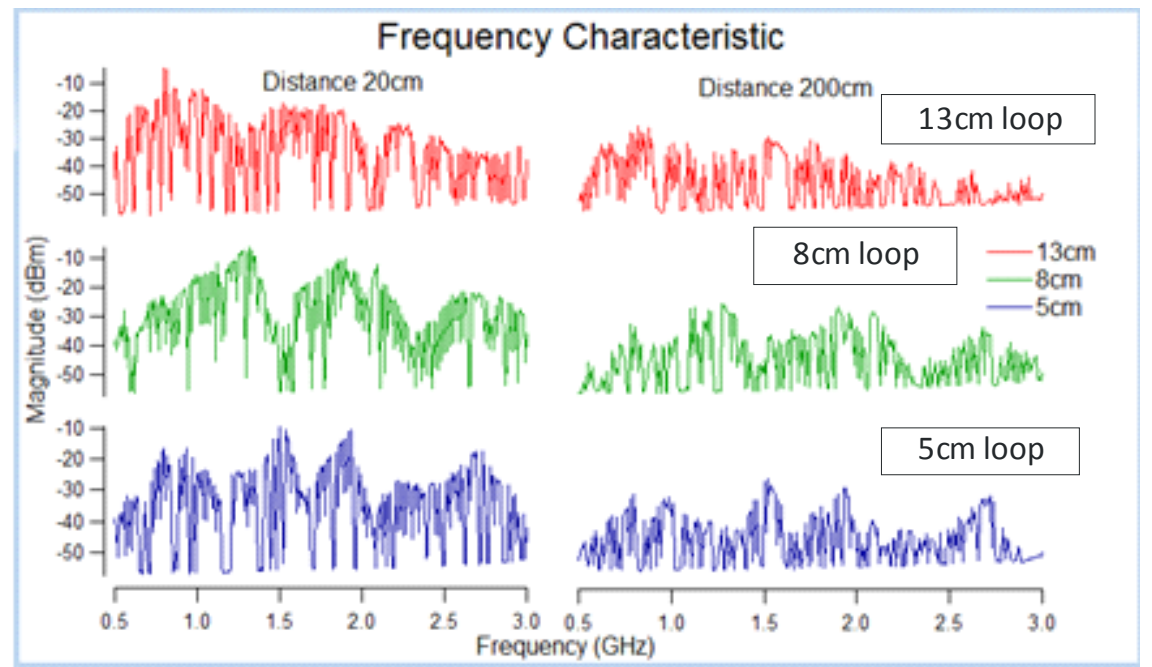

(d)

Figure 2. S11 and frequency characteristics of three loop sensors (a) $13 \mathrm{~cm}$ diameter (b) $8 \mathrm{~cm}$ diameter (c) $5 \mathrm{~cm}$ diameter and (d) detailed characteristics for $20 \mathrm{~cm}$ and $200 \mathrm{~cm}$ away from horn antenna $(500 \mathrm{MHz} \sim 3 \mathrm{GHz})$ 
Sriyono, et al.

The experimental result of frequency characteristics are shown in Figure 2. (d). The three sensors exhibit the distinct distance effect of signal response attenuated by about $10 \mathrm{dBm}$ per every meter. With $2 \mathrm{~m}$ away from the signal source, the detected signal was reduced by about $20 \mathrm{dBm}$. It is verified byS11 parameter tested with the same setup as in Figure 1. (b) that loop sensor of $5 \mathrm{~cm}$ diameter shows the highest frequency response around 1,600 $\mathrm{MHz}$ and loop sensors of $8 \mathrm{~cm}$ and $13 \mathrm{~cm}$ in diameter indicate their peak response values around 1,300 $\mathrm{MHz}$ and around $800 \mathrm{MHz}$, respectively.

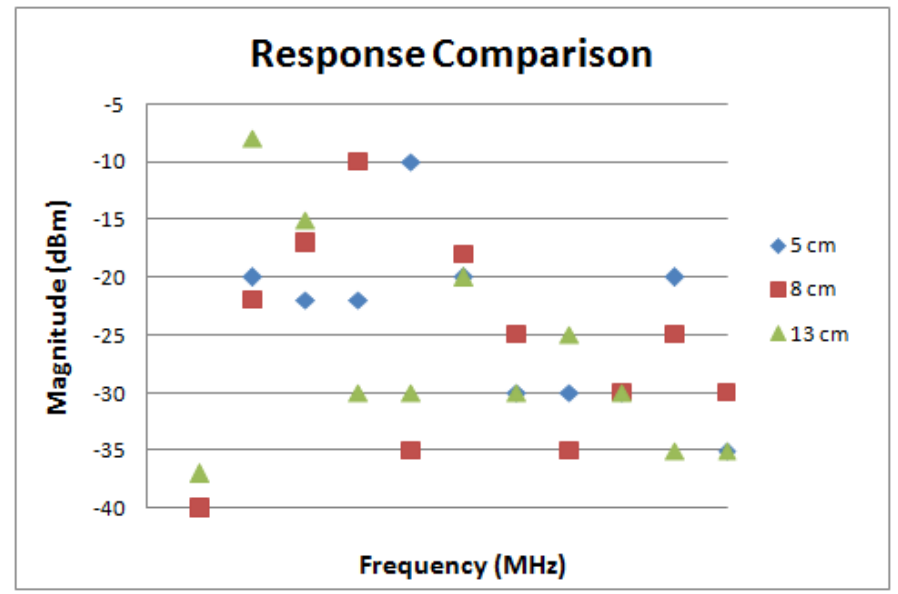

Figure 3. Relative response among three loop sensors with diameter of 5, 8 and $13 \mathrm{~cm}$

Therefore, it would be said that as the sensor diameter increases from $5 \mathrm{~cm}$ to $13 \mathrm{~cm}$, the resonance frequency $(>-5 \mathrm{~dB})$ decreased from $1,600 \mathrm{MHz}$ to $800 \mathrm{MHz}$.

\section{Experiment With Pulse Signal}

In this experiment the loop sensors were subjected to a simulated PD pulses. The simulated PD pulse signal has 1 nano second rise time and 5V magnitude. The signal was injected to GIS conductor through $10 \mathrm{pF}$ coupling capacitor. The signal level injected was corresponded to $50 \mathrm{pC}$. The detected wave shapes are shown in figure 3.

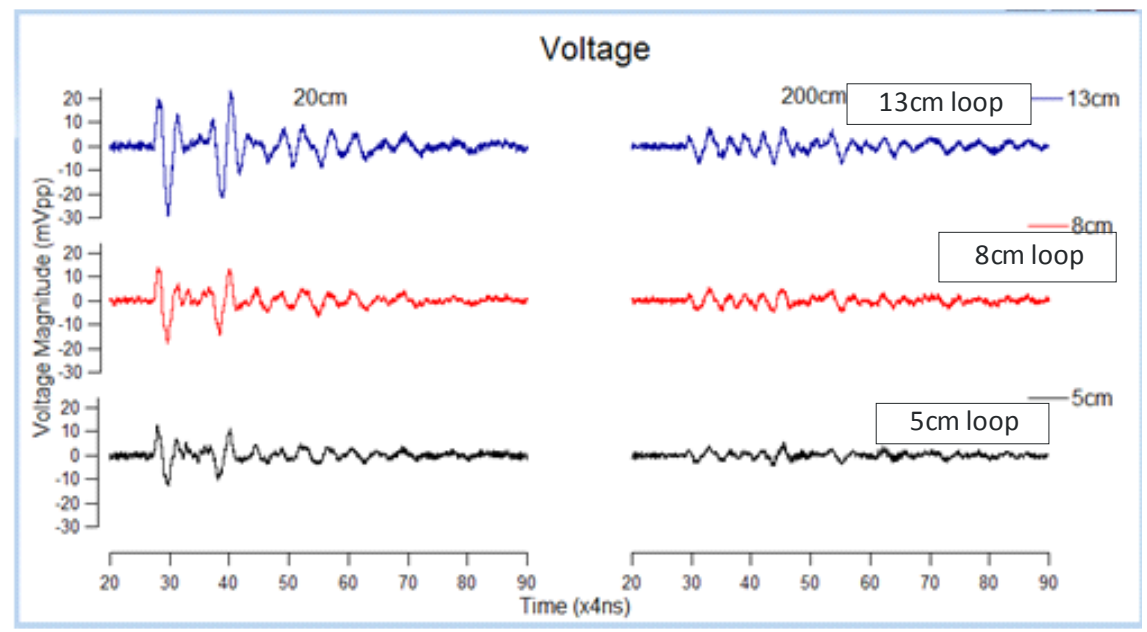

Figue 3. Detected waveshapes by three loop sensors (20 $\mathrm{cm}$ and $200 \mathrm{~cm}$ away from GIS bushing) 


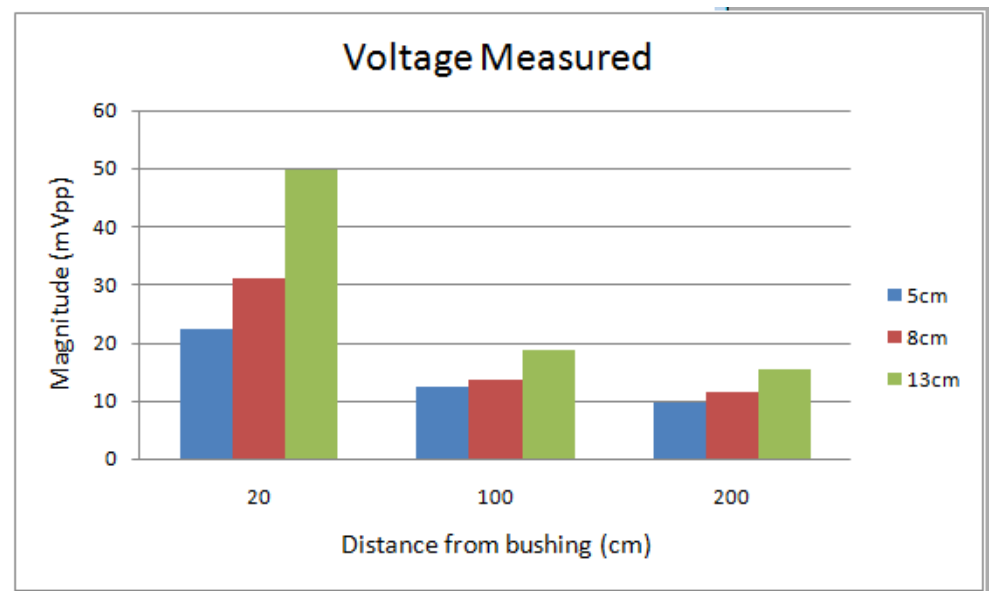

Figure 4. Signal attenuation v.s. distance from GIS bushing

The voltage measured for each antenna diameter as function of distance are shown in figure 4. The results indicated that the larger the diameter the higher the detected voltage.

\section{Experimental setup for partial discharge measurements}

In order to provide the basic data for on-site or on-line application of a loop sensor, experiments were conducted on $66 \mathrm{kV}$ GIS model $\left(\mathrm{SF}_{6}, 0.15 \mathrm{MPa}\right)$. Experimental circuit is shown in Figure 5.

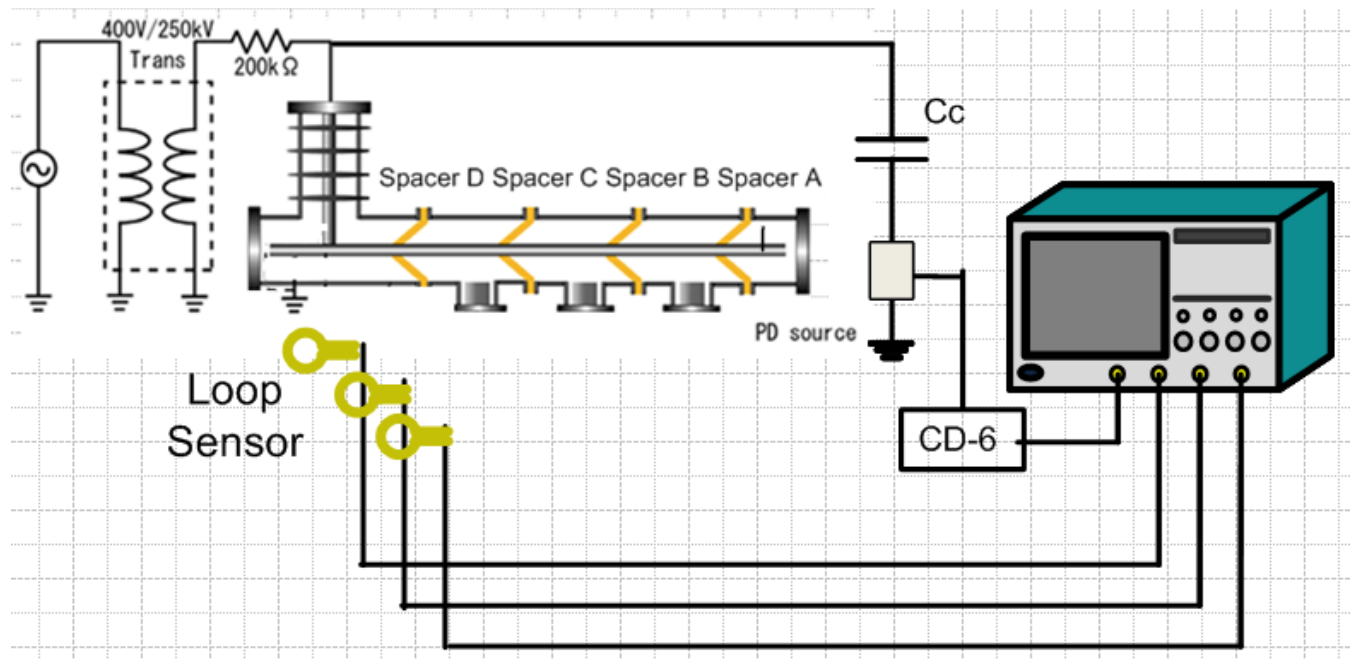

Figure 5. Experimental setup on $66 \mathrm{kV}$ GIS model

The three loop sensors were used to measure PD signals leaked from GIS bushing, installed $20 \mathrm{~cm}, 100 \mathrm{~cm}$ and $200 \mathrm{~cm}$ away in sequence from the bushing as shown in Figure 5 . On the other hand, PD sources were installed at the opposite end of GIS enclosure about $5 \mathrm{~m}$ away from GIS bushing.UHF signals emitted from a PD source were detected by the loop sensors and those signals were transmitted to a digital oscilloscope (YokogawaDL9240, frequency band : $1.5 \mathrm{GHz}$, sample rate: $10 \mathrm{GS} / \mathrm{s}$, record length: $6.25 \mathrm{M}$ ) and a spectrum analyzer (Agilent E4404B up to $6.7 \mathrm{GHz}$ ) for the further analysis of PD spectroscopy in time domain and in frequency domain, respectively. 
Sriyono, et al.

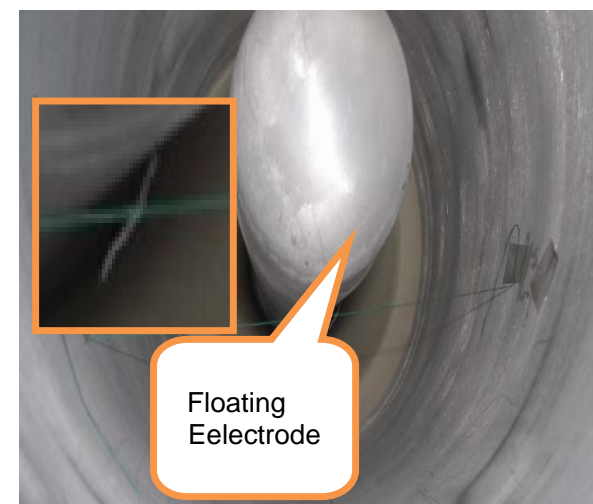

(a)

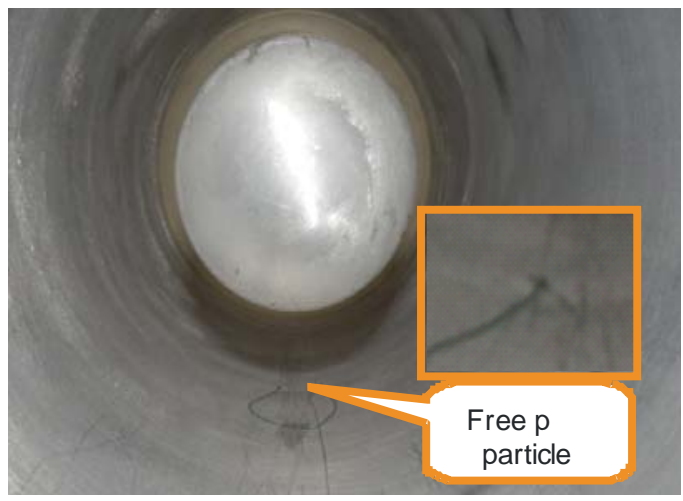

(b)

Figure 6. Installation view of PD source

(a)Floating metallic particle (b) Free metallic particles

At the first step, a floating metal electrode of $10 \mathrm{~mm}$ length was installed using isolated string floated $5 \mathrm{~mm}$ away from the high voltage conductor (Figure 6. (a)). PDIV recorded was around $32 \mathrm{kV}$. PD magnitude at $36 \mathrm{kV}$ corresponded to about $60 \mathrm{pC}$. For the second experiment, we attached two free metallic particlesof $5 \mathrm{~mm}$ length at each end of isolated string(Figure (b)). PDIV for this type of PD was around $35 \mathrm{kV}$. We applied voltage up to $40 \mathrm{kV}$ and clearly identified PD level corresponding to $30 \mathrm{pC}$ measured $200 \mathrm{~cm}$ away from the GIS bushing.

\section{Results and discussions}

\section{A. Floating metallic particle}

Figure 7 shows frequency spectra of PD from this defect type. It is found that there are three dominant frequency bands such as $65 \sim 100 \mathrm{MHz}$ (I), 300 340 MHz (II) and 750 800 $\mathrm{MHz}$ (III). Loop sensors shows higher sensitivity in lower dominant frequency bands (I) and (II). However, their sensitivity in $750 \mathrm{MHz} \sim 800 \mathrm{MHz}$ (III)is rather lower than (I) and (II).

This result coincides with the waveshapes obtained from the oscilloscope as shown in Figure 8. Unfortunately, lower frequency bands (I) and (II) are more vulnerable to external noise than higher frequency band (III). Especially in the range of 50 200 MHz, external noise level is much higher than one of PD signals. The most useful frequency band having less external noise is suggested to be around $300 \mathrm{MHz}$ for these type of the loop sensors.

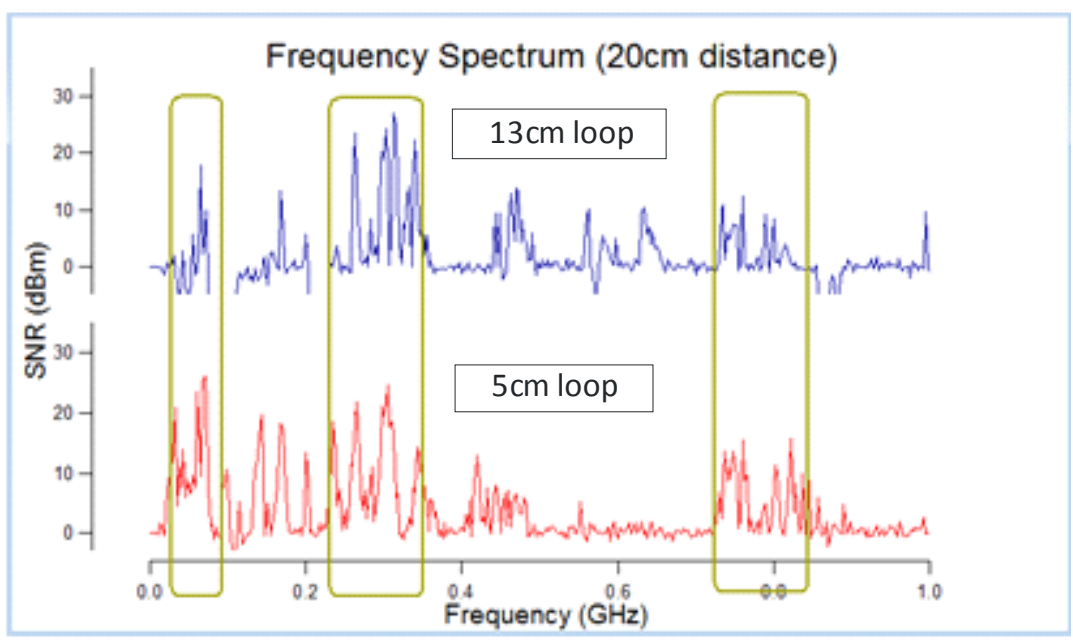

Figure 7. Frequency spectrum for floating metallic particle 


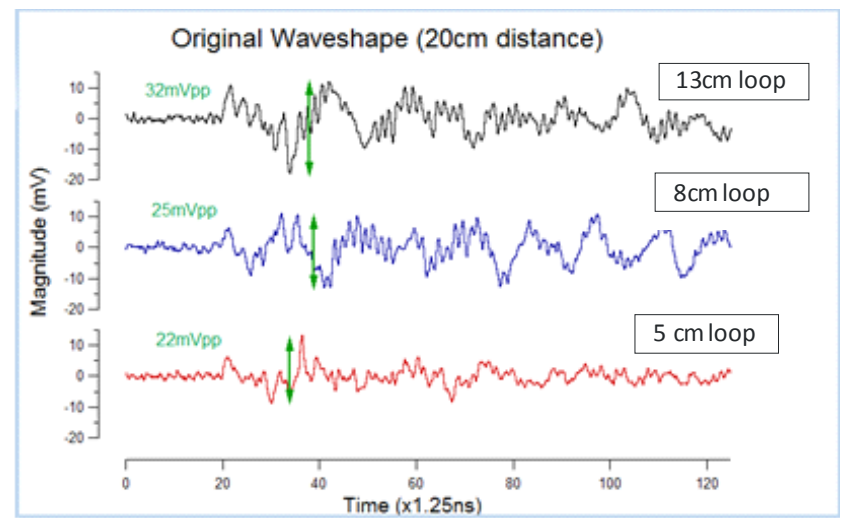

Figure 8. PD waveshapes for floating metallic particle

For more detail analysis, frequency spectrum analyzer exploiting zero span mode ( $3 \mathrm{MHz}$ bandwidth, $16.67 \mathrm{~ms}$ sweep time synchronized to $60 \mathrm{~Hz}$ )was applied to obtain PRPD patterns.

Figure 9 shows PRPD patterns of floating metallic particle for the three loop sensors collected in five frequency bands of 65, 100, 300, 340 and 750MHz. Amongst PRPD patterns measured around $750 \mathrm{MHz}$, loop sensor of $13 \mathrm{~cm}$ diameter shows higher sensitivity than the other loop sensors, which confirms higher $\mathrm{S} 11$ value $(780 \mathrm{MHz},-21 \mathrm{~dB})$ as illustrated in Figure2. (d). However, PRPD patterns in lower frequency bands $(65 \mathrm{MHz}$ and $100 \mathrm{MHz})$ revealed higher noise level due to VHF radio communication.

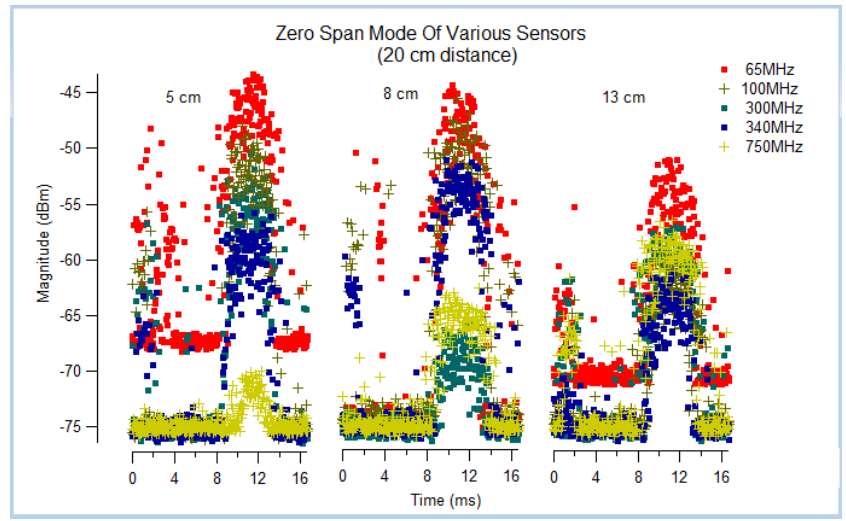

(a) $20 \mathrm{~cm}$ distance from bushing

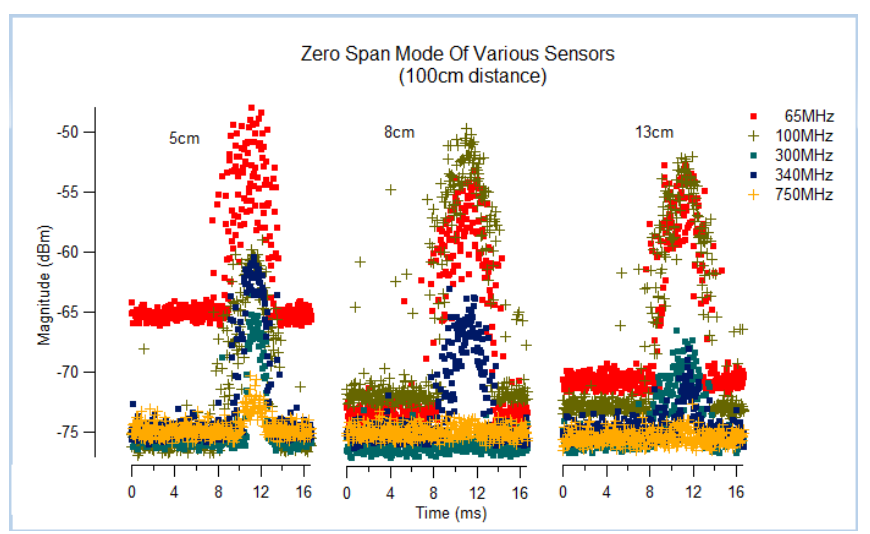

(b) $100 \mathrm{~cm}$ distance from bushing 
Sriyono, et al.

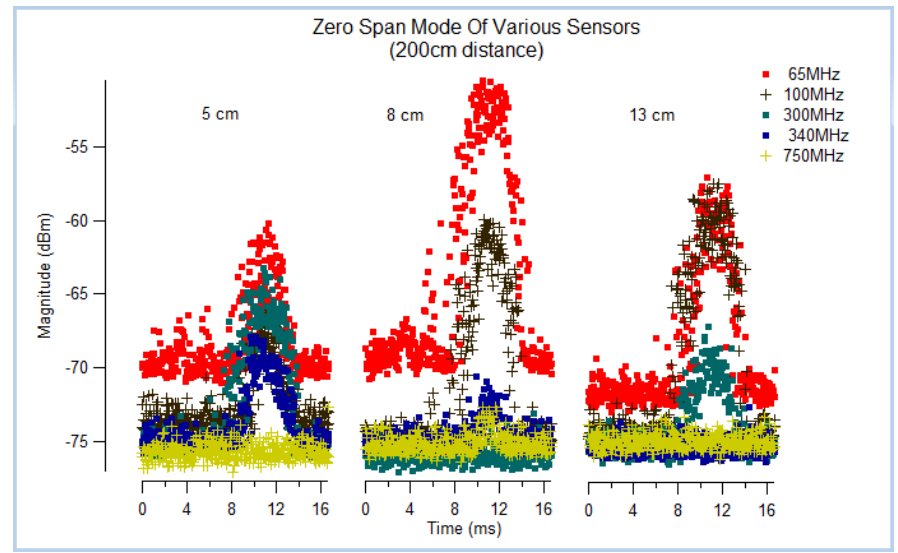

(c) $200 \mathrm{~cm}$ distance from bushing

Figure 9. Zero span mode (PRPD) for floating metallic particle

\section{B. Free metallic particle}

Figure 10 shows frequency spectra of typical PD signalsobtained from free metallic particles. Several dominant frequency bands are also illustrated in 50 200 MHz (I), 300 350 $\mathrm{MHz}$ (II) and $750 \sim 800 \mathrm{MHz}$ (III), which are similar to the previous resultsof the floating particle experiment.Leaked PD signals of $50 \sim 200 \mathrm{MHz}$ and $300 \sim 350 \mathrm{MHz}$ are in TEM mode that propagate along the high voltage conductor and then leaked from GIS bushing. PD signals in $750 \sim 800 \mathrm{MHz}$ propagate along GIS enclosure in TE mode. The sensitivity level of TEM mode signals in 50 200 MHz shows the highest but with the largest noise level.

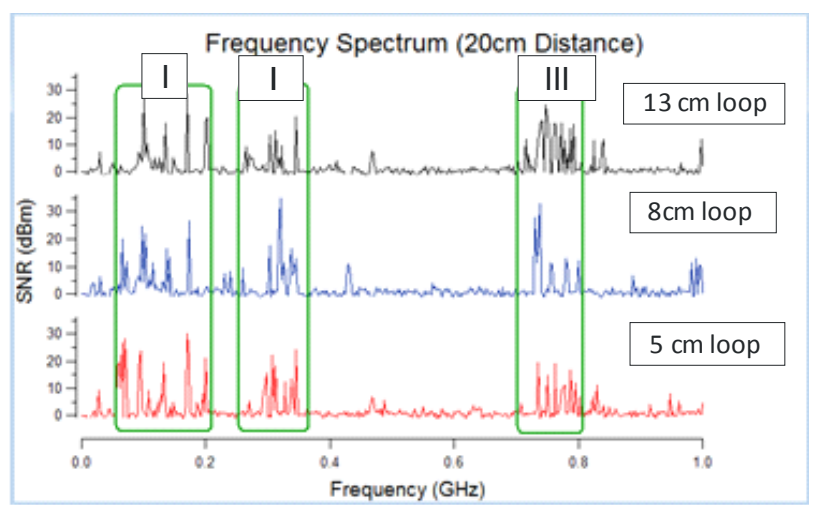

Figure 10. Frequency response for free metallic particle

However, Figure 11 shows that PD waveshapes from free particles experiment contain higher frequency components than one from the floating particle, which should be explained with further analysis.

As expected in Figure 12, PRPD patterns obtained from the free metallic particles experiment illustrate the scattered PD activities all over the phase angle. This typical PRPD pattern could be explained as sporadic movement of free particles.

According to the previous results, the loop sensors have sensitivity of $30 \mathrm{pC}$ to detect leakage PD from the GIS bushing. With additional amplifier and proper filter, higher sensitivity may be achieved. According to the sensitivity test results, the loop sensors are also applicable for PD measurements on the transformers but not directly applicable without any amplifier for PD measurements on GIS. 


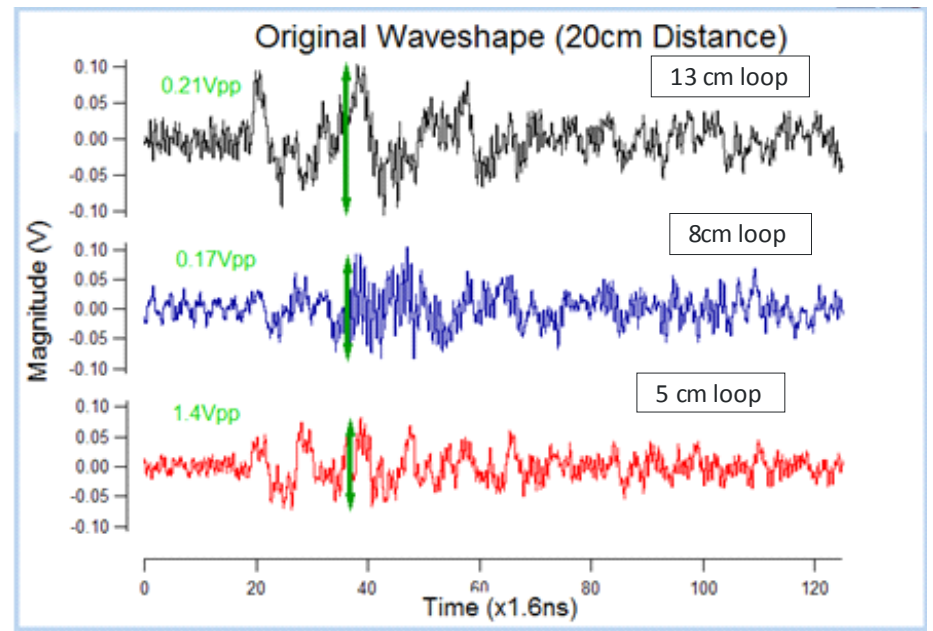

Figure 11. Original waveshapes for free metallic particle

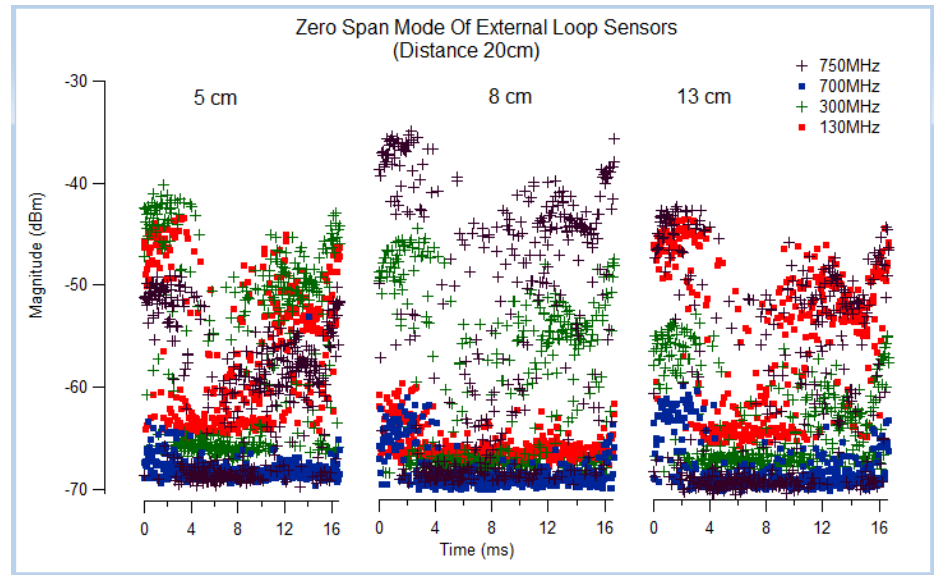

(a) $20 \mathrm{~cm}$ distance from bushing

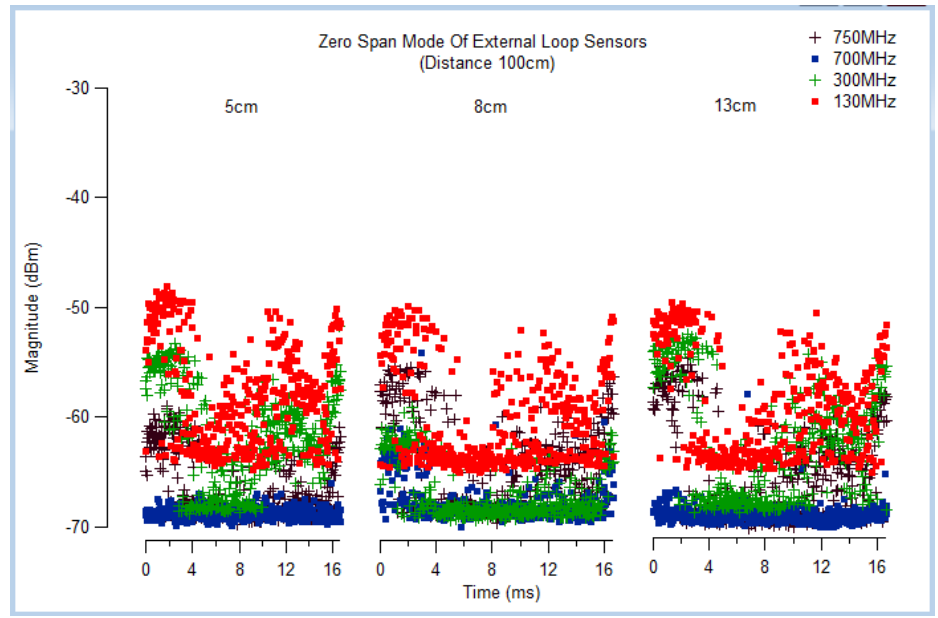

(b) $100 \mathrm{~cm}$ distance from bushing 


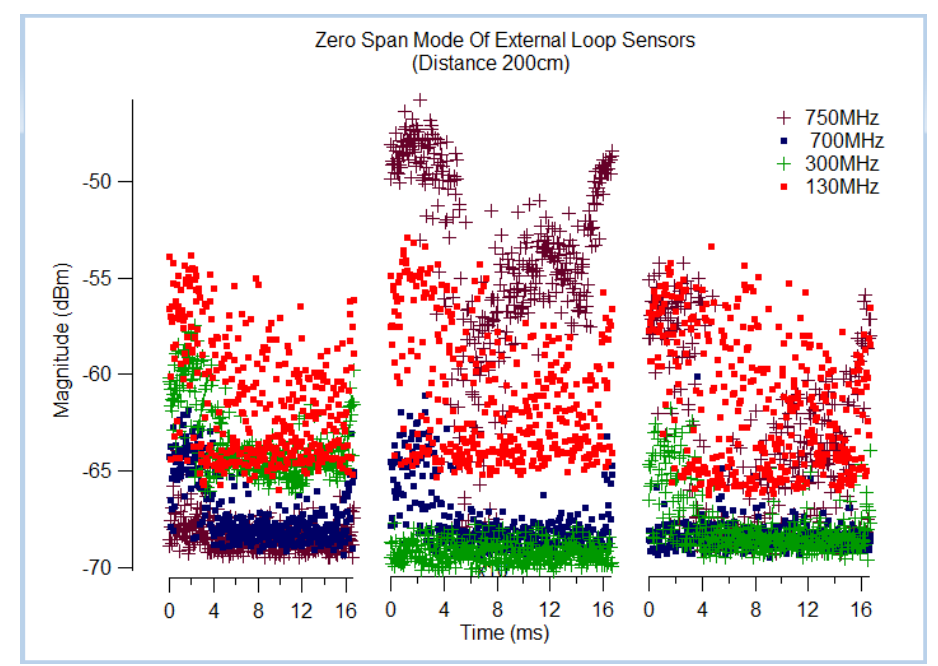

(c) $200 \mathrm{~cm}$ distance from bushing

Figure 12. Zero span mode (PRPD) for free metallic particle

\section{Conclusion}

From the characteristic test on the three loop sensors and their laboratory experiment on 66 $\mathrm{kV}$ GIS model, several conclusions are suggested as follows.

The loop sensor fabricated in laboratory tells us the distinct effect, which signal response was attenuated about $10 \mathrm{~dB}$ per meter.

For S11 experiment, as the loop sensor diameter increases from $5 \mathrm{~cm}$ to $13 \mathrm{~cm}$, the resonance frequency $(>-5 \mathrm{~dB})$ is decreased from $1,600 \mathrm{MHz}$ to $800 \mathrm{MHz}$.

From simulated PD pulse injection experiment (1ns rising time), the center frequency of detected signal by the loop sensor was around $200 \mathrm{MHz}$, which propagated GIS conductor in TEM mode. The largest loop sensor of $13 \mathrm{~cm}$ diameter shows the highest response among three sensors.

The loop sensor shows PD sensitivity level corresponding to $30 \mathrm{pC}$ measured $200 \mathrm{~cm}$ away from GIS bushing. The result suggests that higher sensitivity less than $10 \mathrm{pC}$ could be achieved with proper shielding and suitable filter design.

The domain PD frequency bands obtained from two experiments (free particles and floating metalic particles) are similar in their ranges of 50-200 Mhz, 300-350 Mhz, and 750-800 MHz. Leaked PD signals of 50-200 MHz and $300-350 \mathrm{MHz}$ are in TEM mode that propagate along the high voltage conductor and then leaked from GIS bushing. PD signals in $750-800 \mathrm{MHz}$ propagate along GIS enclosure in TE mode. The sensitivity level of TEM mode signals in 50$200 \mathrm{MHz}$ shows the highest but with the largest noise level.

Detection of leaked PD signal in TEM mode of $300 \sim 350 \mathrm{MHz}$ frequency band are suggested to be the best option for PD diagnosis system due to its higher sensitivity with less external noise level.

This technique could be applied to PD detection system for high voltage power transformer.

\section{References}

[1]. Y. Takahashi, Diagnostic Methods for Gas-Insulated Substations, IEEE Trans. Electr. Insulation, Vol. 21, No. 6, 1986, pp. 1037-1043

[2]. T. Huecker, J. Gorablenkow, UHF Partial Discharge Monitoring and Expert System Diagnosis, IEEE Trans. Power delivery, Vol. 13 No. 4, 1998, pp/1162-1167

[3]. Umar Khayam, Nobuko Otaka, Takakazu Matsuyama, Yoshiki Takehara, Shinya Ohtsuka, Masayuki Hikita,"Examination of Single-phase PDM Device for PD Diagnosis on Three-phase GIS", International Journal on Electrical Engineering and Informatics, Vol. 2 No. 3, pp. 244-255, 2010. 
[4]. S. Meijer, J.J. Smit, UHF defect Evaluation in Gas Insulated Equipment, IEEE Trans on Dielectrics and Electrical Insulation, Vol. 12, No. 2, 2005, pp. 285-296

[5]. Suwarno , Caesario P., Anita P.' Partial Discharge Diagnosis of Gas Insulated Station (GIS) Using Acoustic Method, Int. Conf. Electr. Eng. And Informatics, Kualalumpur, August, 2009, pp. 667-671

[6]. S. Kaneko, S. Okabe, M. Yoshimura, H. Muto, M. Kamei, Partial Discharge Diagnosis Method using Electromagnetic Wave Mode Transmission in Actual GIS Structure, IEEE Trans on Dielectrics and Electrical Insulation, Vol. 15, No. 5, 2008, pp. 1329-1339

[7]. Umar Khayam, T. Hoshino, T. Nakajima, S. Maruyama, K. Nishigouchi, M. Kozako, M. Hikita,"Characteristics of PD Induced Electromagnetic Wave Propagating through TBranch of $154 \mathrm{kV}$ GIS in the Presence of Epoxy Spacer, Proc. 2012 IEEE International Conference on Condition Monitoring and Diagnosis, Bali, September 2012, pp. 379-383.

[8]. S. Rud, J. Mac Arthur, M. Judd, A generic Knowledge-based Approach to the Analysis of Partial Discharge Data, IEEE Trans on Dielectrics and Electrical Insulation, Vol. 17, No. 1, 2010, pp. 149-156

[9]. M. Hikita, S. Ohtsuka and S. Matsumoto, "Recent trend of the PD measurement technique using the UHF electromagnetic wave detection method," IEEJ Trans. on Elect and Electr. Eng. Vol.2 Issue 5, pp.504-509, 2007

[10]. S.Kaneko, S. Okabe, M Yoshimura, H. Muto, C. Nishida and M. Kamei, "Detecting characteristics of various antennas on partial discharge electromagnetic wave radiating through insulating spacer in gas insulated switchgear", IEEE Trans. on Dielectrics and Electrical Insulation, Vol. 16 No. 5,pp.1462-1472, 2009

[11]. Microchip, “AN678 : RFID coil design“,Microchip Technology Inc., 1998

[12]. T. Hoshino, H. Koyama, S. Maruyama, and M. Hanai: "Comparison of Sensitivity between UHF Method and IEC 60270 Standard for on-site Calibration in Various GIS", 15th International Symposium on High Voltage Engineering, Slovenia, 2007, paper T7264.

[13]. M. Knapp, R.Feger, K. Feser:"Application of The CIGRE Sensitivity Verification for UHF PD Detection in Three-Phase GIS", 11th International Symposium on High Voltage Engineering, London, 1999, Vol. 5, pp. 82-85.

[14]. M.D. Judd, O. Farish: "High Bandwidth Measurement of Partial Discharge Current Pulses", ISEI Paper of IEEE Vol. 2, June 1998, pp 436-439.

[15]. H. Muto, M. Doi, H. Fuji, M. Kamei: "Resonance Characteristics and Identification of Modes of Electromagnetic Waves Excited by Partial Discharges in GIS”, Electrical Engineering in Japan, Vol. 131, No. 2, 2000, pp. 1-11.

[16]. H. Imagawa, K. Emoto, H. Murase, H. Koyama, S. Wakabayashi, T. Sakakibara, E. Haginomori: "Frequency Domain Discussions on PD Signal Propagation Characteristics in GIS", Electrical Engineering in Japan, Vol. 133, No. 3, 2000, pp. 9-17.

[17]. S. Ohtsuka, M. Onomoto, T. Teshima, S. Kaneko, S. Okabe, M. Hikita,'Influence of GIS Tank Size on First Incoming PD Induced Electromagnetic Wave in Terms of Risk Assessment of GIS”, IEEJ Transaction on Power and Energy, Vol. 124-B, No. 11, pp. 1365-1372, 2004.

[18]. S. Meijer, E. Gulski, J.J. Smith,"Pattern Analysis of Partial Discharges in SF6 GIS", IEEE Trans. on DEI, Vol.5 No. 6, pp. 830-842, 1998.

[19]. Sriyono, Widya Anggoro Putro, K. Nishigouchi, Umar Khayam, Suwarno, M. Kozako, M. Hikita, K. Urano, C. Min, Sensitivity verification and determination of the best location of external UHF sensors for PD measurement in GIS, Proc. 2012 IEEE International Conference on Condition Monitoring and Diagnosis, Bali, September 2012, pp. 698-701. 


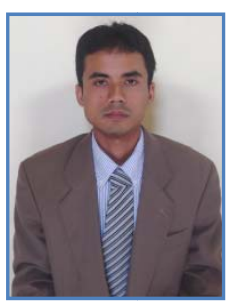

Sriyono received Bachelor in Engineering and Master in Engineering from Bandung Institute of Technology, Indonesia in 2004 and 2012, respectively. He worked in Indonesia Electrical Company, PT PLN (Persero) P3B Sumatera, UPB Sumbagteng (National Grid electricity) as Scada and Telecommunication Engineer during $2004-$ 2012. Since 2012 he is working in Indonesia Electrical Company, PT PLN (Persero) PUSLITBANG as High Voltage and Power System Engineer. During 2011-2012 he is visiting student in Hikita Laboratory, Kyushu Institute of Technology, Japan. His research interest is partial discharge measurement in high voltage equipment.

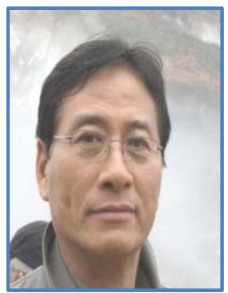

Yong-Joo Kim achieved Bachelor of Engineering in Seoul National University, 1975; Master of Science in Electric Power Engineering, Rensselaer Polytechnic Institute, 1984; and Doctor of Philosophy in Electric Power Engineering, Rensselaer Polytechnic Institute, 1987. Dr. Kim is Vice President, Korean Institute of Electrical Engineers, 2008-2010; Vice President, CIGRE-Korea, 2005-2008; President, B Society, Korea Institute of Electrical Engineers, 2008; Conference Co-Chairman, CMD (Condition Monitoring \& Diagnosis) 2006; and Conference Chairman, ICEMS (International Conference on Electrical Machines and System) 2007. Dr. Kim is Visiting Researcher, Kyushu Institute of Technology, Japan during 2011-2012. His research interest is diagnosis of high voltage equipment using partial discharge measurement.

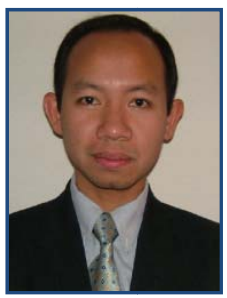

Umar Khayam was born in Indonesia in 1975. He received B.Eng. with honor (cum laude) and M.Eng. degrees in electrical engineering from Bandung Institute of Technology (ITB), Indonesia, in 1998 and 2000, respectively. He received Doctor Degree in Electrical Engineering from Kyushu Institute of Technology(KIT), Japan in 2008. He was a researcher at Hikita Laboratory, KIT, Japan, during 2008-2009 and 2010-2012. He is a Lecturer at School of Electrical Engineering and Informatics ITB, Indonesia. Currently, he is the Head of High Voltage and High Current Engineering Laboratory, ITB. His research interests include the partial discharge measurement and phenomena in electric power apparatus. Dr. Umar Khayam received Best Paper Award in 2005 KJ Symposium on Electrical Discharge and High Voltage Engineering. Dr. Umar Khayam is General Secretary of 2012 IEEE International Conference on Condition, Monitoring, and Diagnosis (CMD). He is member of IEEE.

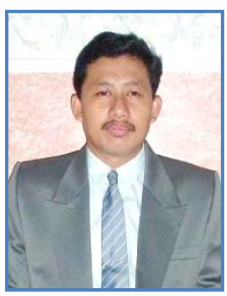

Suwarno was born in Indonesia in 1965. He received BSc and MSc from The Department of Electrical Engineering, Bandung Institute of Technology, Bandung, Indonesia in 1988 and 1991 respectively. He received PhD from Nagoya University, Japan in 1996 in the field of High Voltage Electrical Insulation. Suwarno is a professor in The School of Electrical Engineering and Informatics Institut Teknologi Bandung and currently he is the Dean of the School. Suwarno is a member IEEE.

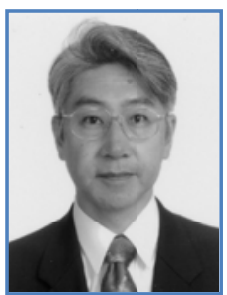

Masayuki Hikita (M'96-SM'00) was born in 1953. He received B. S., M. S. and Dr. degrees in electrical engineering from Nagoya University of Japan, in 1977, 1979, and 1982, respectively. He was an Assistant, a Lecturer, an Associate Professor at Nagoya University in 1982, 1989, and 1992, respectively. Since 1996, he has been a professor of the Department of Electrical Engineering, Kyushu Institute of Technology. He was a Visit Scientist at the High Voltage Laboratory in MIT, USA, from August 1985 to July 1987. Dr. Hikita has recently been interested in research on development of diagnostic technique of electric power equipment. He is a member of the Japan Society of Applied Physics and the IEEJ. He is now a senior member of the IEEE. 